\title{
Experimental study on flame propagation over overload-wire under varying inclination Angle
}

\author{
Hu Wen ${ }^{1}$, Xiangtao Zhao ${ }^{1, *}$, Qing Tian ${ }^{1}$, Weifeng Wang ${ }^{1}$, He Jian $^{2}$ \\ ${ }^{1}$ School of Safety Science and Engineering, Xi'an University of Science and Technology, Xi' an 710054, China \\ ${ }^{2}$ State grid Shaanxi province power company maintenance company, Xi'an 710054, China
}

\begin{abstract}
To better understand the process of fire caused by conducting wire, based on the study of overload of the low-voltage wire, the theoretical analysis of flame spread mechanism of overload-wire was proposed, and the functional relationship between flame shape characteristics and flame spread speed, current, and inclination angle was studied. The results show that: (1) the theoretical model of flame propagation can well reflect the changes of thermodynamic parameters in the process of flame propagation, and it is in better agreement with the experimental results. (2) When the current value is constant, with the increase of the inclination angle of the wire $\left(0^{\circ}-90^{\circ}\right)$, the flame is elongated along the wire direction, the width of the flame base increases, and the angle between the flame front and the wire decreases. When the inclination angle is fixed, with the increase of the inclination angle of the conductor, the flame shape becomes more "high and wide" and the flame height increases at the same time. (3) When the current is constant, the flame spread rate increases with the increase of wire inclination angle; when the inclination angle is constant, the flame spread rate decreases sharply with the increase of current.
\end{abstract}

\section{Introduction}

Many related studies have shown that the inclination angle has a significant effect on the fire spread characteristics of the solid surface. Quintiere et al. [1] used hardened RPU plates to carry out upward and downward fire spread experiments and found that the inclination angle of the experimental samples has a significant effect on the fire spread rate. Great influence. Zhang Ying [2] discussed the influence of the tilt angle on the spread of flame on the surface of the wood and studied the mechanism of flame spread acceleration. Drysdale and Macmillan et al. [3] conducted upward fire propagation experiments in "hot thin" and "hot thick" PMMA, and found that when the sample placement angle changes from horizontal $0^{\circ}$ to $75^{\circ}$, the average flame propagation rate is almost No change; when the inclination angle is changed from $75^{\circ}$ to $90^{\circ}$, the flame spread rate increases greatly. Hu Longhua et al. [4] studied the influence of the tilt angle on the flame spread rate (FSR) on wires with high thermal conductivity and derived a simplified FSR calculation model. Zhu Keke [5] studied the flame rate of horizontal, upward, and downward spreading of the wire under the inclination angle of $-75^{\circ}$ to $+75^{\circ}$, and conducted an in-depth discussion from the basic flame shape. In actual scenes such as building fires, the wire is not only placed horizontally, but the inclined state of the wire also has a significant impact on its combustion behavior [6-9]. The buoyancy acting on the pyrolysis gas will affect the flame shape and the unburned molten insulation layer through gravity [10-13]. Buoyancy will have a more complex effect on the forward propagation of the flame. Therefore, it can be inferred that the flame shape and flame spread rate of the overcurrent wire with a certain inclination angle are quite different from the horizontal and vertical spread.

For wires placed at a certain angle, increasing the current through the wire will increase the Joule heat generated by the inner core of the wire and change the heat conduction of the wire to the insulating layer. At the same time, the natural convection between the insulating layer and the outside air will strengthen, and the induced buoyancy will also The increase will further affect the basic flame shape and flame spread rate. Therefore, this article will study the flame spread characteristics of wires passing different currents under different inclination angles.

\section{Experimental}

This experimental system consists of four parts: (1) The power rectifier circuit system, through which the current and voltage output is controlled by the current output regulation system; (2) The current output regulation system, through which the voltage can be adjusted and output Voltage $220 \mathrm{~V} / 380 \mathrm{~V}$, voltage acquisition frequency $1.5 \times 104 \mathrm{~Hz}$; current adjustment range is $30 \sim 300 \mathrm{~A} \mathrm{DC}$ or $\mathrm{AC}$, current output accuracy can be controlled within $\pm 0.1 \mathrm{~A}$; and the control system has two modes: automatic mode and manual mode; (3) over Electric current test bench system. The test bench system is composed of upper and lower parts: the upper prism-shaped smoke exhaust device; the lower part is a $1500 \mathrm{~mm}(\mathrm{D}) \times 1200 \mathrm{~mm}(\mathrm{~W}) \times$

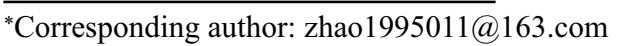


2000mm (H) rectangular parallelepiped closed test bench space, inside the space The test bench and insulated wooden blocks are $1200 \mathrm{~mm}$ high for over-current experiments; (4) The connection device adopts a quick- release structure to connect the experimental samples and the power supply terminal. The schematic diagram of the experimental system is shown in Figure 1.

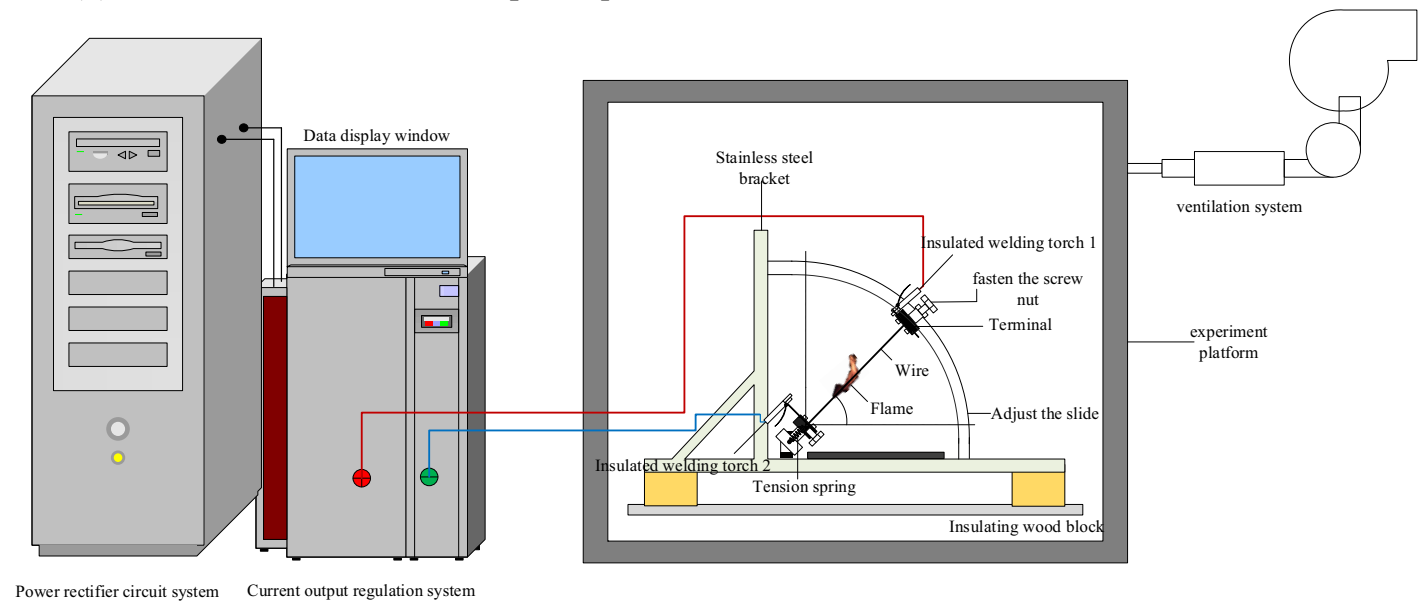

Figure 1. Overcurrent test bench for wire

This article mainly focuses on the study of the combustion characteristics of low-voltage conductors. Wire(PVC) is selected. As shown in Table 1. The wires are measured to a length of $540 \mathrm{~mm}$, and the length of the insulation layer of about $20 \mathrm{~mm}$ at both ends of the wire is removed. The experimental wire parameters are shown in Table 1.

Table 1. Basic physical parameters of experimental wires

\begin{tabular}{|c|c|c|c|c|c|c|}
\hline Sample & $\begin{array}{c}\text { Core diameter } \\
(\mathrm{mm}) \\
d c\end{array}$ & $\begin{array}{c}\text { Insulation } \\
\text { thickness }(\mathrm{mm}) \\
\delta p\end{array}$ & $\begin{array}{c}\text { Sample } \\
\text { diameter } \\
(\mathrm{mm}) \\
d 0\end{array}$ & $\begin{array}{c}\text { The ratio of } \\
\text { Core section } \\
\text { area } A c / A 0(\%)\end{array}$ & $\begin{array}{c}\text { The ratio of } \\
\text { insulation } \\
\text { section area } \\
A p / A 0(\%)\end{array}$ & $\begin{array}{c}\text { Rated } \\
\text { current } \\
(\mathrm{A}) \\
\text { Ie }\end{array}$ \\
\hline $\begin{array}{c}\mathrm{Cu}- \\
\mathrm{PVC}\end{array}$ & 1.38 & 0.8 & 2.98 & 21.44 & 78.56 & 32 \\
\hline
\end{tabular}

During the stable phase of the wire flame spread, the CCD camera ( $1000 \mathrm{fps}, 1920 \times 1280$ pixels, 72 pixels/inch $)$ was used to record the burning phenomenon at a shooting rate of 1000 frames per second, and the position of the flame front was marked. Figure 4 shows the position of the flame front. By drawing the time history curve of the flame front position, the slope of the curve is fitted and calculated, and the fire spread rate (unit: $\mathrm{m} / \mathrm{s}$ ) is obtained through proportional conversion (the actual length is $5 \mathrm{~cm}=2.8$ pix $)$.
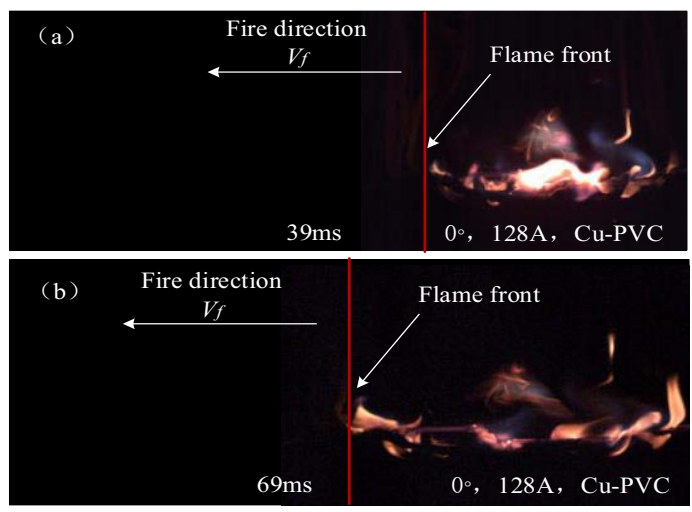

Figure 2. Change in the position of the leading edge of the wire

\section{Theoretical analysis of flame spreading process}

The PVC insulation material of the wire in this study is considered to be a kind of thermal thin material $(\delta$ $\mathrm{p}=0.8 \mathrm{~mm}<<1 \mathrm{~mm}$ ) [14]. Therefore, the temperature profile of the entire PVC insulation layer or the inner core crosssection can be considered uniform, the spread rate of the flame mainly depends on the thermal feedback of the combustion zone in the front of the flame to the preheating zone. As shown in Figure 3 , by $\dot{Q}_{1}, \dot{Q}_{2}$ and $\dot{Q}_{3}$ respectively represent the heat convection between the flame and the exposed part of the core, the heat convection between the flame and the insulating layer, and the heat conduction through the inner core constitute the thermal feedback of the flame front combustion zone. The heat radiation and heat conduction are mainly controlled by the heat input of the flame, and the heat conduction $Q_{3}$ is mainly caused by the Joule heating effect of the wire during the electrification process. Therefore, the heat balance of the combustion zone can be expressed as follows $[15,16]$ :

$$
\frac{\pi}{4}\left(d_{0}^{2}-d_{c}^{2}\right) \rho_{p}\left[c_{p} V_{f}\left(T_{p}-T_{a}\right)+S\right]+\frac{\pi}{4} d_{c}^{2} \rho_{p} c_{p} V_{f}\left(T_{p}-T_{a}\right)=\dot{Q}_{1}+\dot{Q}_{2}+\dot{Q}_{3}
$$




$$
\begin{gathered}
\dot{Q}_{1}=h_{p}\left(T_{f}-T_{p}\right) \\
\dot{Q}_{2}=(1-\exp (-k l)) \sigma\left(T_{f}^{4}-T_{p}^{4}\right) \\
\dot{Q}_{3}=\lambda_{p}\left(T_{c}-T_{p}\right) \\
\dot{Q}_{3}=\lambda_{p}\left(T_{f}-T_{p}\right) \chi=\lambda_{p}\left(T_{f}-T_{p}\right) /\left[\left(\lambda_{c} d_{c}+4 h_{c} F_{h}\left(F_{l}-F_{h}\right)\right) / 4 h_{c} F_{h}\left(F_{l}-F_{h}\right)\right]
\end{gathered}
$$

Among them $\rho_{p},{ }^{c_{p}}$ and $V_{f}$ respectively represent the density of the PVC insulation layer, the specific heat of the PVC insulation layer, and the flame spread rate of the PVC insulation layer; $S, h_{p}$, and $\lambda_{p}$ respectively represent the pyrolysis latent heat, convective heat transfer coefficient, and thermal conductivity of the insulation layer; $k, l$ and $\sigma$ respectively Soot absorption coefficient, characteristic length and Boltzmann constant; $T_{a}, T_{p}$ and $T_{f}$ respectively represent the ambient temperature, insulation temperature, flame temperature; $T_{c}$ represent the metal core temperature; $h_{c}, F_{l}$ and $F_{h}$ respectively the heat transfer coefficient of the inner core of the combustion zone, flame width, and length.

Therefore, through (1), (2), (3), (4), and (5) equations, we can get the flame spread rate as follows:

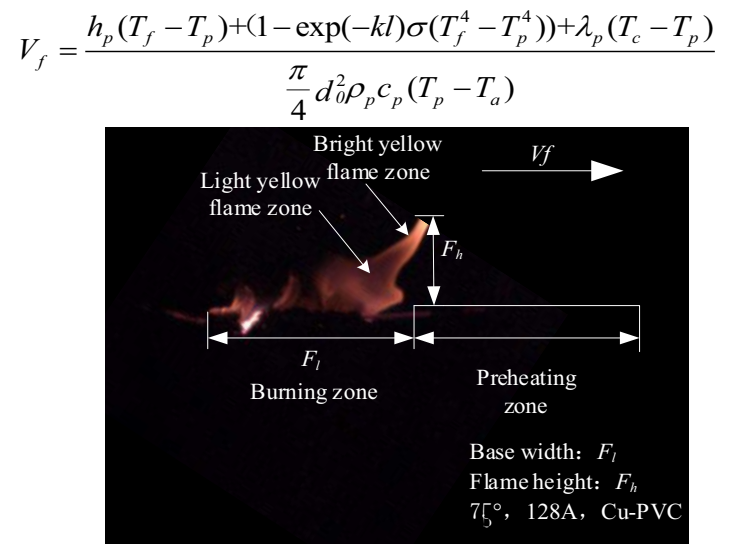

Figure 3. Flame structure diagram

\section{Results and discussion}

\subsection{Flame characteristics}

Figure 4 shows the flame shape corresponding to varying overcurrent conductors at the same time under varying inclination angles of copper core (Cu-PVC). The Figure 4 shows the flame image corresponding to the inclination

\begin{tabular}{|c|c|c|c|c|c|}
\hline $\begin{array}{c}\text { Inclination } \\
\text { angles }\end{array}$ & $4.0 \mathrm{Ie}$ & $4.5 \mathrm{Ie}$ & $5.0 \mathrm{Ie}$ & $5.5 \mathrm{Ie}$ & $6.0 \mathrm{Ie}$ \\
\hline $0^{\circ}$ & & & & & \\
\hline $15^{\circ}$ & d & & & & \\
\hline $30^{\circ}$ & & & & & \\
\hline $45^{\circ}$ & & & & & \\
\hline $60^{\circ}$ & & & & & \\
\hline $75^{\circ}$ & $\Leftrightarrow \rightarrow$ & exé. & $=\infty$ & $\Rightarrow$ & $=2 \times-$ \\
\hline $90^{\circ}$ & 1 & 8 & $\frac{1}{2}$ & 3 & \\
\hline
\end{tabular}
angle of the wire in the experimental conditions from $0^{\circ}$ to $90^{\circ}$, and the values of overcurrent are $4.0 \mathrm{Ie}, 4.5 \mathrm{Ie}, 5.0$ Ie, 5.5 Ie, 6.0 Ie. It can be found from the Figure 4:

Figure 4. Typical flame characteristics corresponding to different overcurrent conductors at the same time under different inclination angles 
For a wire with a certain inclination angle: (1) The flame shape becomes more "high and wide" under the condition of higher overload current, and the flame height also increases at the same time. This is because the wire is under the same environmental conditions, the higher overload current makes natural Convection increases, and induced buoyancy increases. At the same time, the diffusion rate of the insulating layer accelerates, and the burning rate of the flame increases. As the overload current value increases, the flame will be stretched due to the increase in buoyancy, the flame profile gradually becomes sharp, and the flame height increases as a whole Trend, the width of the flame base is gradually widening; (2) When the overload current value is higher, due to the enhancement of the buoyancy driving effect, the pyrolysis gas at the flame base burns more fully and the burning rate is faster, and the area of the light yellow flame area is larger. With the increase of the current value, the proportion of bright yellow flame area gradually decreases, and the proportion of light yellow flame area gradually increases.

For a certain overload current condition: (1) As the inclination of the wire gradually increases $\left(0^{\circ} \sim 75^{\circ}\right)$, the flame is elongated along the direction of the wire, and the width of the flame base becomes larger. The width of the flame base when the wire is placed horizontally is the smallest At the same time, the angle between the flame front and the wire becomes smaller, and the distance between the flame and the wire surface is smaller (flame height), which is more conducive to the thermal feedback between the flame and the wire surface, and accelerates the spread of the flame from the combustion zone to the preheating zone. Speed; (2) With the gradual increase of the inclination of the wire $\left(0^{\circ} \sim 75^{\circ}\right)$, the area of the light yellow flame area becomes larger and the area of the bright yellow area increases, indicating that the combustion is more complete.

It is worth noting that when the inclined spreading at a low angle $\left(15^{\circ}\right)$, it is found that the flame shape has periodic spreading changes. Due to the particularity of the angle, the liquid melt of the insulating layer that cannot be burned and consumed will move towards the wire under the action of gravity. Flow distribution in the opposite direction of flame spread.

From the above discussion, it is found that at the inclination angle $\left(75^{\circ}\right)$, the angle between the flame and the wire becomes smaller, and the flame is more "flat", approaching $0^{\circ}$. Therefore, compare the vertical spread $\left(90^{\circ}\right)$ shape of the wire with the dip spread $\left(75^{\circ}\right)$, as shown in Figure 5 below.

\begin{tabular}{|c|c|c|c|c|c|}
\hline $\begin{array}{c}\text { Inclination } \\
\text { angles }\end{array}$ & 4.0Ie & $4.5 \mathrm{Ie}$ & $5.0 \mathrm{Ie}$ & $5.5 \mathrm{Ie}$ & $6.0 \mathrm{Ie}$ \\
\hline $75^{\circ}$ & E & is & , & $\vec{k}$ & 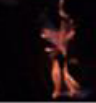 \\
\hline $90^{\circ}$ & 1 & 3 & $\dot{x}$ & 2 & 8 \\
\hline
\end{tabular}

Figure 5. Vertical spread $\left(90^{\circ}\right)$ shape and oblique spread $\left(75^{\circ}\right)$ flame shape under different current conditions

From Figure 5, it is found that when the current is constant, the flame spreading at an inclination angle $\left(75^{\circ}\right)$ is more "slender" than the flame spreading vertically $\left(90^{\circ}\right)$, and the miscellaneous flame is accompanied at the top of the flame, while the flame spreading vertically $\left(90^{\circ}\right)$ has no miscellaneous Flame, flame propagation is also more stable.
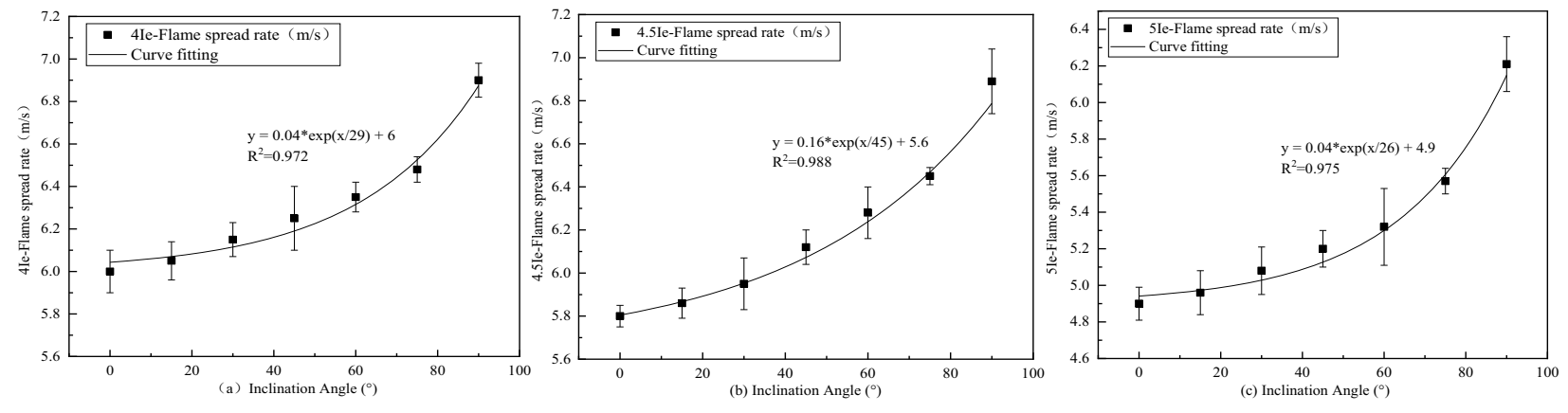

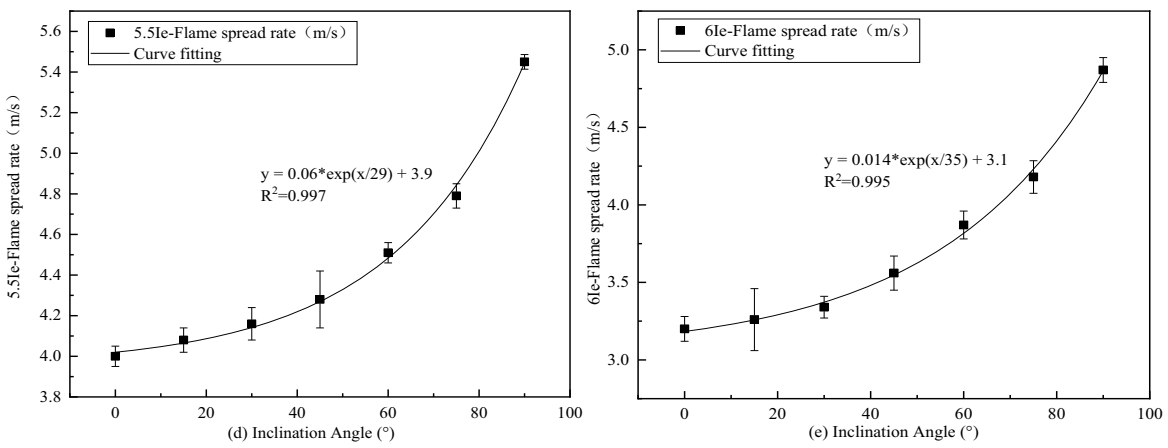

Figure 6. Variation of flame spread rate of copper core wire with wire inclination under different current conditions

It can be found in Figure 6:

(1) For wires with different inclination angles, the thickness of the insulating layer is the same, and the current is constant, the flame spread rate increases as the inclination angle of the wire increases. Under different energized current conditions, the flame spread rate changes with the inclination angle the same, the flame spread rate is the smallest at the horizontal inclination angle, and the flame spread rate reaches the maximum at the vertical inclination angle. Due to the gradual increase of the inclination angle of the wire $\left(0^{\circ} \sim 75^{\circ}\right)$, the flame is elongated along the direction of the wire, the width of the flame base becomes significantly larger, and the angle between the flame front and the outer surface of the wire becomes smaller, which is more conducive to the flame and the insulating layer. Thermal feedback between the time, increasing the rate of flame spread.

(2) Data fitting of angle and flame spread speed found: when using ExpDec1 mathematical model equation for different energized current values and inclination angles, the goodness of fitting is higher, and the fitting equation can be used to calculate the difference in different inclination angles. The flame spread rate is predicted and judged.

\subsection{The effect of electric current on flame spread rate}

Figure 7 shows the variation of flame spread speed with inclination angle under different current conditions.
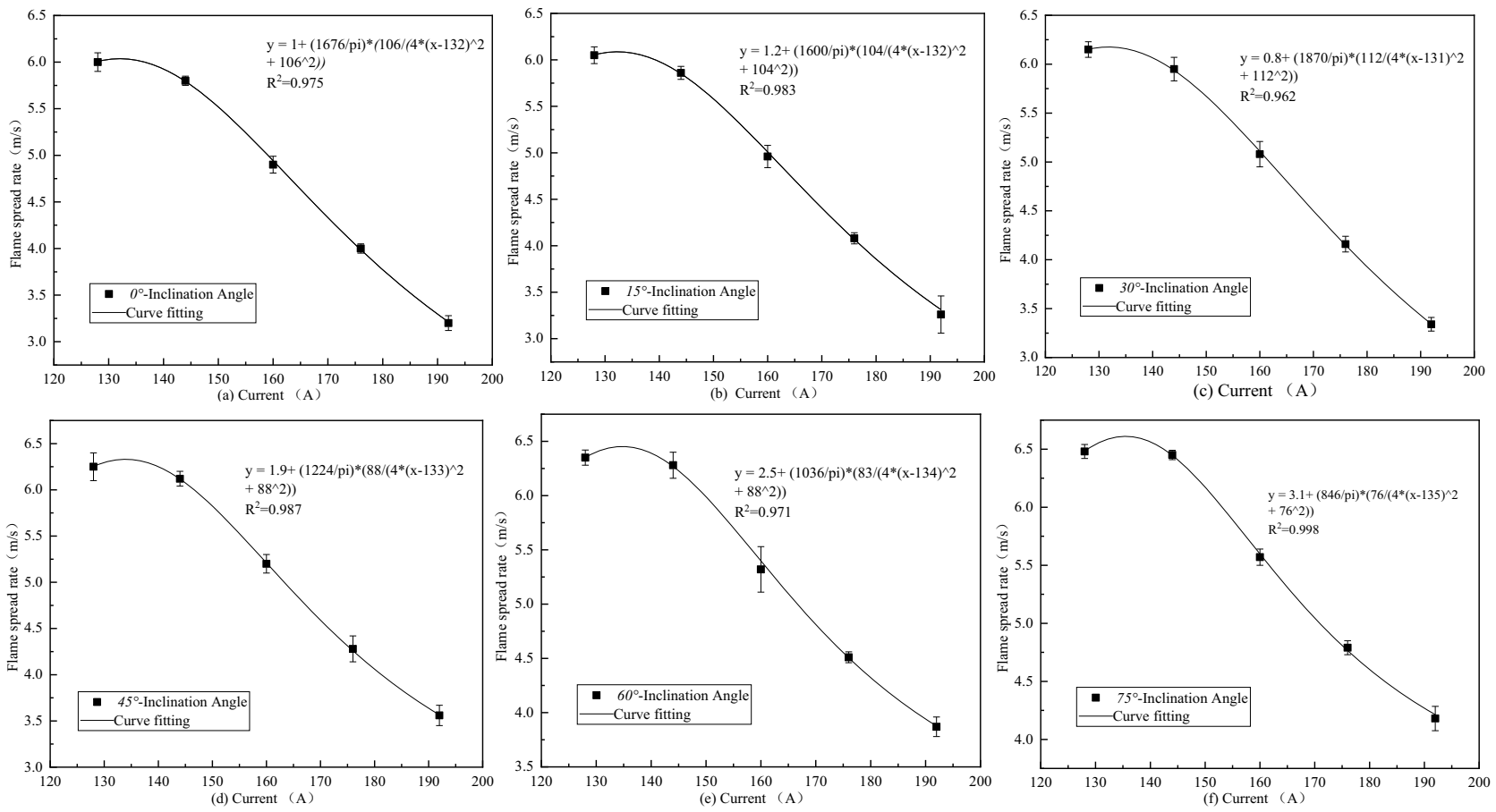


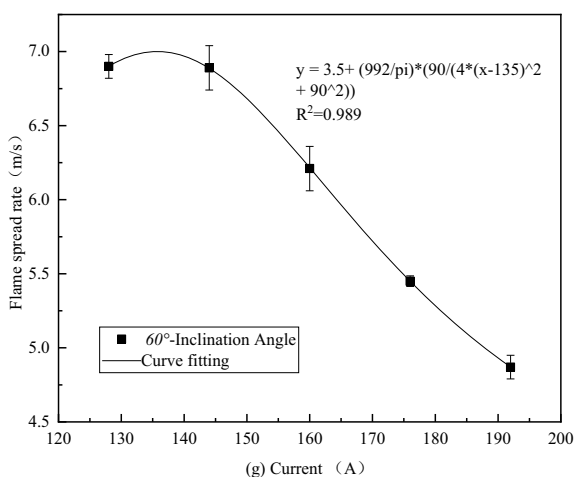

Figure 7.Variation Law of Flame Spreading Speed with Current under Different Inclination Angle

It can be seen from Figure 7:

(1) When the inclination angle is constant, as the current increases, the flame spread rate drops sharply, mainly because the energized wire starts to pyrolyze due to the Joule heating effect, and the generated pyrolysis gas and air form a preliminary Diffusion of mixed gas, as the current increases, the rate of pyrolysis gas generation in the insulating layer continues to increase, thereby affecting the flame spread rate;

(2) When the Lorentz mathematical model equation is used between the flame spread rate and the current, the goodness of fit is high, and the flame spread rate under different current conditions can be predicted and judged by the fitting equation.

\section{Conclusions}

(1) the theoretical model of flame propagation can well reflect the changes of thermodynamic parameters in the process of flame propagation, and it is in better agreement with the experimental results.

(2) When the current value is constant, with the increase of the inclination angle of the wire $\left(0^{\circ}-90^{\circ}\right)$, the flame is elongated along the wire direction, the width of the flame base increases, and the angle between the flame front and the wire decreases, When the inclination angle is fixed, with the increase of the inclination angle of the conductor, the flame shape becomes more "high and wide" and the flame height increases at the same time.

(3) When the current is constant, the flame spread rate increases with the increase of wire inclination angle; when the inclination angle is constant, the flame spread rate decreases sharply with the increase of current.

\section{References}

1. ZHOU Y, BU R, YI L, et al. Heat transfer mechanism of concurrent flame spread over rigid polyurethane foam: Effect of ambient pressure and inclined angle [J]. International Journal of Thermal Sciences, 2020, $155(106403$.

2. ZHANG Y, JI J, WANG Q, et al. Prediction of the critical condition for flame acceleration over the wood surface with different sample orientations [J]. Combustion and Flame, 2012, 159(9): 2999-3002.
3. DRYSDALE D D, MACMILLAN A J R. Flame spread on inclined surfaces [J]. Fire safety journal, 1992, 18(3): 245-254.

4. HU L, ZHANG Y, YOSHIOKA K, et al. Flame spread over the electric wire with high thermal conductivity metalcore at different inclinations [J]. Proceedings of the Combustion Institute, 2015, 35(3): 2607-2614.

5. SHIMIZU K, KIKUCHI M, HASHIMOTO N, et al. A numerical and experimental study of the ignition of insulated electric wire with long-term excess current supply under microgravity $[\mathrm{J}]$. Proceedings of the Combustion Institute, 2017, 36(2): 3063-3071.

6. TAKANO Y, FUJITA O, SHIGETA N, et al. Ignition limits of short-term overloaded electric wires in microgravity $[\mathrm{J}]$. Proceedings of the Combustion Institute, 2013, 34(2): 2665-2673.

7. HUANG $\mathrm{X}$, NAKAMURA Y, WILLIAMS F A. Ignition-to-spread transition of externally heated electrical wire $[\mathrm{J}]$. Proceedings of the Combustion Institute, 2013, 34(2): 2505-2512.

8. TAKAHASHI S, TAKEUCHI H, ITO H, et al. Study on unsteady molten insulation volume change during flame spreading over wire insulation in microgravity $[\mathrm{J}]$. Proceedings of the Combustion Institute, 2013, 34(2): 2657-2664.

9. KOBAYASHI Y, KONNO Y, HUANG X, et al. Effect of insulation melting and dripping on opposed flame spread over laboratory simulated electrical wires [J]. Fire Safety Journal, 2018, 95(1): 1-10.

10. FUJITA O, KYONO T, KIDO Y, et al. Ignition of electrical wire insulation with a short-term excess electric current in microgravity $[\mathrm{J}]$. Proceedings of the Combustion Institute, 2011, 33(2): 2617-2623.

11. KIKUCHI M, FUJITA O, ITO K, et al. Experimental study on flame spread over wire insulation in microgravity; proceedings of the symposium (international) on combustion, Fire Safety Journal, 1998 [C]. Elsevier.

12. MIYAMOTO K, HUANG X, HASHIMOTO N, et al. Limiting oxygen concentration (LOC) of burning polyethylene insulated wires under external radiation [J]. Fire Safety Journal, 2016, 86(32-40. 
13. FANG J, ZHANG Y, HUANG X, et al. Dripping and Fire Extinction Limits of Thin Wire: Effect of Pressure and Oxygen [J]. Combustion Science and Technology, 2019, 1-16.

14. LEUNG C, STAGGS J, BRINDLEY J, et al. The effects of an inert central core on the thermal pyrolysis of an electrical cable [J]. Fire safety journal, 2000, 34(2): 143-168.
15. HUANG X, REN Z, ZHU H, et al. A modified zone model on vertical cable tray fire in a confined compartment in the nuclear power plant [J]. Journal of Fire Sciences, 2018, 36(6): 472-493.

16. KIM Y, HOSSAIN A, NAKAMURA Y. Numerical modeling of melting and dripping process of polymeric material subjected to moving heat flux: Prediction of drop time [J]. Proceedings of the Combustion Institute, 2015, 35(3): 2555-2562. 